https://doi.org/10.31426/ijamsr.2018.1.9.915

International Journal of

\title{
THE EFFECTS OF INSTRUCTION OF CORPUS-BASED CONJUNCTION MATERIALS ON IRANIAN EFL LEARNERS' WRITING ABILITY
}

\author{
Zahra Beheshti Sefat \\ MA, Alzahra University, Tehran, Iran
}

zhrbeheshti@gmail.com

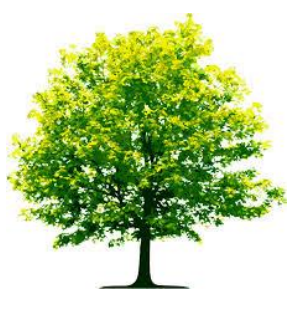

Keywords: English conjunction, corpus-based instruction, writing ability, coherence.

\begin{abstract}
A B S T RA C T
Electronic language corpora and their accompanying concordance software have outgrown their usefulness as a construct for teaching and learning. However, little has been done to examine the effectiveness of corpus-based materials in Iran. Thus, this study takes the advantage of the opportunities offered by the availability of corpus resources to teach English conjunctions to Iranian EFL learners in order to improve their writing ability. To meet this end two corpus-based conjunction units based on the semantic forces of each conjunction and the accompanying authentic examples drawn from the British National Corpus (BNC), utilizing the MonoConc Pro (2.2), were designed for 30 undergraduates fresh women EFL learners who were later assigned into two groups namely control and experimental. In order to come up with the sound results, three similar conjunction tests, an essay writing test and a perception questionnaire were used. The data collected were analyzed through SPSS software. Results indicated that the members of the experimental group outperformed the control group and there was a statistically significant difference between the experimental and control groups in both conjunction and essay writing tests. In addition, the participants' answers to the questionnaires revealed that they held a positive attitude toward the corpus-based instruction.
\end{abstract}

Citation: Zahra Beheshti Sefat (2018). The Effects Of Instruction Of Corpus-Based Conjunction Materials On Iranian Efl Learners' Writing Ability. International Journal of Advanced Multidisciplinary Scientific Research (IJAMSR) ISSN:2581-4281 Vol 1, Issue 9, November, 2018, \#Art.915, pp 43-54 


\section{Introduction}

The concept of coherence is of central importance to discourse analysis. In writing a coherent text much attention has been paid to" the first criterion for textuality: 'cohesion', the apparent connections in discourse"(Renkema, 1993).

Halliday and Hassan (1976) distinguish five types of cohesive ties: substitution, ellipsis, reference, conjunction, and lexical cohesion. In this study, our focus is on conjunctions. Conjunction is a relationship which indicates how the subsequent sentence or clause should be linked to the preceding or the following sentence, and how this can be achieved by the use of conjunctions (Renkema, 1993).

Conjunctions are of many types. Four frequently occurring types are added, adversity, causality, and temporality (as it is displayed in British National Corpus 2001). Writing is the skill that most of our students in Iran have difficulty with. One of the major problems is that they cannot properly link what they have in mind with what they put on paper. Actually, when they change thoughts into words, they come up with some unrelated, messy sentences which do not have a unity in meaning i.e. coherence. This is because of their inability to use cohesive devices appropriately and adequately. My own experiences as an English teacher have shown that Iranian EFL students have many problems in using conjunctions. Therefore, as the computers have become smaller, cheaper and thus more widely available, both to teachers and to learners and the data stored on them has become more readily accessible to the user, the practical prerequisites for corpus-based teaching and learning have improved dramatically. So the purpose of the present study is to examine whether the practice with corpus-based materials can help students learn how to use conjunctions in creating a coherent text. To meet this end the following research questions are posed:

a) Do corpus-based conjunction materials in comparison with traditional materials have any effect on Iranian EFL learners' writing ability?

b) Does the use of corpus- based materials in comparison with traditional materials result in a reduction of Iranian EFL learners' errors in essay writing?

c) Does the use of corpus-based materials by Iranian EFL learners in comparison with traditional materials have any effect on the retention of what they have learned after a period of 2 weeks?

d) Does the use of corpus-based materials change Iranian EFL learners' attitudes about learning conjunctions?

\section{Literature Review}

Writing, the ability to express ideas through the words, is a basic communication skill which is often slighted in English language classes. It is like a channel through which the writer communicates meaning. The communication of meaning is achieved through a process of situated interpretation in which readers infer writers' underlying strategies and intentions by interpreting the linguistic cues which contextualize their messages. Such cues are called contextualization cues. 


\section{International Journal of Advanced Multidisciplinary Scientific Research (IJAMSR) ISSN:2581-4281}

They provide an interpretive framework for the referential content of a message (Schiffrin, 1986). One of the key factors in a successful communication of meaning is text coherence. Text coherence depends on the writer's successful integration of different contextualization devices to situate a message in an interpretive frame. Conjunctions are one of these contextualization devices. The term conjunctions and conjunctive devices are derived from the Halliday and Hasan's description of textual cohesion in English (1976). The function of conjunctions is to express the logical flow of the text explicitly and to contribute to the interpretation of the text. They serve as a grammatical resource to specify additive, adversative, causal and temporal relations between and within sentences (Tseng and Liou 2005).

Therefore, they should be taught to the native and nonnative English learners. But unfortunately they are neglected to some extent, especially in EFL classes. Even as late as 1970, L2 writing was not viewed as a language skill to be taught to learners. Instead, it was used as a support skill in grammar, reading and... in language learning. As the theory and practice of L2 composition writing gradually developed, it followed the path of US native English speaker composition theory. Only recently has an English L2 composition theory and pedagogy begun to offer insights and pedagogical practices (Carter and Nunan 2001).

Research results have shown that the use of the conjunction is a distinguishing element between natives and non-natives' writing style in both the overuse and underuse of them as well as the misuse of specific conjunctions. Field and Yip (1992), for instance, conducted comparative analysis of cohesive devices in the essays of native speakers and Cantonese speakers who were fluent writers in English. It was shown that these Hong Kong students used to far more link devices than their English-speaking counterparts. Within such a general tendency, however, both overuse and underuse of particular devices were detected. Less formal adverbial conjuncts such as actually and besides, occurred repeatedly, whereas formal ones, like furthermore, were usually rare in learners' texts.

There can be different causes of misuse of conjunctive devices, e.g. inappropriate textbook design, L1 transfer, and wrong strategies for teaching. To center for the teaching of coherence in writing, explicit form-focused instruction promises to arouse learners' awareness of coherence-creating devices, including cohesive connectors (Tseng and Liou 2005).

Therefore, the present study looks at one particular trend in teaching conjunction that has emerged recently in teaching methodologies, namely Computer Assisted Language Learning (CALL). It is assumed that CALL can be superior to the traditional instructions on several aspects. First data-driven methods with the enhancement of technology can provide learners with numerous authentic examples via consulting corpora online. Rich resources created by web-based concordances may supplement the content of traditional workbooks, which often supply limited or insufficient examples to illustrate conjunction usage. In addition, the feature that renders CALL programs most distinctive is their immediate feedback. Compared with traditional feedback offered by workbooks or teachers, computer feedback is much more face-saving and learner-controlled (Tseng and Liou 2005). Thus, it is presumable that CALL with appropriate design can bring better learning effects in the specific domain of conjunction use. 


\section{International Journal of Advanced Multidisciplinary Scientific Research (IJAMSR) ISSN:2581-4281}

\subsection{Corpus}

Two of the five definitions listed in the second edition of the Oxford English Dictionary (1963) refer to language. The first is that of "A body or collection of writings or the like; the whole body of literature on any subject" (p. 263). Thus we may speak of the 'Shakespearean corpus', meaning the entire collection of texts of Shakespeare. The second is that of "the body of written or spoken material upon which a linguistic analysis is based"(p.

263) (for more information see http://dictionary.oed.com). This is the sense of the word from which the phrase 'corpus linguistics' derives. Sinclair defines linguist's corpus as "a collection of pieces of language, selected and ordered according to explicit linguistic criteria in order to be used as a sample of the language" (1996, p. 76).

A corpus- body of naturally produced language, selected according to some designed and stored in machine readable form- can be investigated by a software program such as concordance that typically produces a KWIC file or a concordance. The plural is corpora.

Sinclair remarks "The language looks rather different when you look at a lot of it at once" (1991, p. 100). Corpora are, ideally, representative samples of a language variety, a genre, or a medium. Regarding the question of corpus size, writers are unanimous in arguing that in principle bigger is better (Sinclair, 1991). The more text there is in a corpus, the more likely it is to give an accurate representation of the language.
Dodd (2000) stresses that a corpus is not a random collection of texts. Its construction is planned according to some design to produce a body of texts which are in some way representative of, for example, a particular field and/or time. Having more than one corpus of a language makes it possible to examine the frequency and distribution of particular words, collocations, or other features across different corpora as well as the same corpus.

Currently, computer corpora may store many millions of running words, whose features can be analyzed by means of tagging (the addition of identifying and classifying tags to words and other formations) and the use of concordancing programs. Corpus examples can enhance frameworks involving explicit presentation of language features, but they are particularly relevant to frameworks which depend on the learners using their existing language knowledge to work out the meaning and use of new elements (Rutherford and SharwoodSmith, 1985). Corpus use is compatible with methodologies that advocate exposure to language, or comprehensible input (Krashen, 1985).

\subsubsection{Corpus- based Conjunction Materials}

As Faghih (2000) states the distinctive characteristics of each type of conjunction should be pointed out to EFL learners, so that they will be able to recognize and/or produce them correctly. Therefore, to center for the teaching of coherence in writing, corpus-based instruction promises to arouse learners' awareness of coherence-creating devices, including connectors, because it helps learners notice the features in the input and has the opportunity to become part of their acquired knowledge. Recognizing the drawbacks of the traditional methods, researchers have proposed several solutions or 


\section{International Journal of Advanced Multidisciplinary Scientific Research (IJAMSR) ISSN:2581-4281}

alternative instruction to counter the problems. First, the connectives introduce to students at any one time should be reduced to a limited set of the more common ones so as to acquaint them with the semantic as well as discuss the value of these items (Crewe, 1990; Granger and Tyson, 1996; Zamel, 1983). Especially for style and register, teachers must play the role of informants to alert students to their non-native usage in order to attain coherence in writing. Besides the textual explanation, authentic illustrative sentences play an essential role in helping learners figure out the logical relationships that these conjunctive device signals (Granger and Tyson, 1996).

\subsection{Computer Assisted Language Learning}

The following two definitions- the first since 1997 and the second from 2005- indicate important changes in perspective:

Computer-assisted language learning (CALL) may be defined as "the search for and study of applications of the computer in language teaching and learning. (Levy, 1997, p.1)

CALL means learners, learning language in any context with, through, and around computer technologies. (Egbert, 2005, p.4)

Whereas the first definition prioritizes "applications of the computer" in its information structure, the second definition not only prioritizes "learners, learning language", but also broadens the potential types of relationships between computer technologies and language learning.
In the 1990s, the personal computer emerged as a significant tool for language teaching and learning. The widespread use of software, local area networks (LANs) and the Internet has created enormous opportunities for language learners to enhance their communicative abilities, both by individualizing practice and by tapping into a global community of other learners (HansonSmith, 2000). Given the high level of integration of digital technology in people's everyday lives in many (but not all) parts of the world, Warschauer (1999) has argued that the term computer-assisted language learning has outgrown its usefulness as a construct for teaching and research.

Coincidental with the development of the multimedia personal computer were the changes in our understanding of the teaching and learning of languages. Communicative approaches (Krashen, 1982) are all enhanced by the use of computers. CALL has branched out in many ways in communicative pedagogy (HansonSmith, 2000). Most current practitioners of CALL stress the importance of authentic language and audience; here the computer aids by allowing language learners to communicate with native speakers around the world over the Internet. In addition, it offers previously impossible options for out-of-class language uses as well as exciting practices for usage practice.

\section{Methodology}

\subsection{Participants}

In this study the participants were 30 undergraduate female English major students studying in Imam Reza University in Mashhad. All of them had received formal instruction in English in Iranian schools for seven years, three years in junior high school and four years in high 


\section{International Journal of Advanced Multidisciplinary Scientific Research (IJAMSR) ISSN:2581-4281}

school. It is worthwhile to mention that in order to be eligible to take part in the study; it was made sure that the participants had taken an English writing as a required course which was offered for one class period per week, lasting for about 90 minutes. Then the learners were divided into two equal-in-number groups (15 each): the experimental and control groups. The criterion for this division was the participants' partial familiarity with how to use the Internet and computer. That is, those who were familiar with the computer and the Internet were assigned as the experimental group and those who were not familiar with $\mathrm{PC}$ were assigned to the control group. Furthermore, the writing subdivision of a recent version of IELTS (2005) was administered in order to ensure that the participants in both groups were homogeneous.

\subsection{Instruments}

Five types of instruments were used in the present study:

a) 1. Test of homogeneity: The writing subdivision of a recent version of IELTS (2005) was administered to check the participants' competency in terms of their ability to write in English. To do so, the learners were asked to write a text with about $150-200$ words in 30 minutes. The topic was" What do you think the advantages of attending school from a young age are?"

b) 2. Supplementary background questionnaire: A 15-item questionnaire was given to learners at the beginning to gain information about their EFL backgrounds, e.g. their level of proficiency in English writing, their problems in learning how to write, their problematic areas in writing English texts. The information gained by means of this questionnaire and the ones collected after the study (the second questionnaire) could provide useful information about learners' personal perception before and after the study.

c) 3. Conjunction tests: Three similar test forms of conjunction items were used in pretest, immediate posttest and delayed posttest in order to assess the knowledge of the participants in the use of conjunctions. Each test has 20 items in the format of 10 gap-filling, 5 scrambled orders and 5 multiple choices. Participants were supposed to answer these conjunction tests in each phase, i.e. of pretest, posttest, and delayed posttest within 25 minutes.

d) 4. Essay writing task: Before and after the study students were required to write two essays in class within 30 minutes in order to check their writing production. These two tests were also borrowed from a recent version of IELTS (2004). In this part the learners were required to write a text with about $150-200$ words including at least 10 conjunctions in 30 minutes. The topics of the two essays before and after the study was "Why I choose English" and "Choosing a language" respectively.

e) 5. The perception questionnaire: After the treatment learners in the experimental group was given a 17-item evaluation questionnaire to obtain their attitudes about the efficacy of corpus-based practices. 


\section{International Journal of Advanced Multidisciplinary Scientific Research (IJAMSR) ISSN:2581-4281}

\subsection{Procedure}

The participants were divided into two groups: the experimental group and the control group. The control group took part in their ordinary classroom programs. The treatment was given to the experimental group. In the first session of the study learners were given the pretest, essay writing task and the supplementary background questionnaire. During the following two weeks, learners took part in online exercises for 90 minutes in each session. At the beginning of the first session, students were connected to the designed webbased pages. Then I as the researcher introduced the conjunction with them through a textual explanation and some examples. Then they clicked the links to enter the corpus and started practicing authentic examples for 45 minutes. Then they were required to go back to the web page and do the exercises. In the fourth session, following the theoretical phase as explained above, since the connection to the Internet was not established, participants used the MonoConc Pro (MP). In the fifth week they took the immediate posttest and another essay writing task and the perception questionnaire. After another 2 weeks they were required to take the delayed posttest.

\section{Results}

The parametric statistic method, T-test, was used to analyze the results of the study in order to find out whether there was any significant difference between the scores of the two groups. Naturally to clarify the findings, descriptive statistics were also provided. To find out the effects of corpus- based conjunction materials on learners' conjunction competences, the total scores of both the experimental and control groups in pretest and posttest were compared using a matched $\mathrm{T}$ - test. To score the participants' essays, again a rubric like the one mentioned above was utilized. The scores gained here were compared using a matched T- test. It is worth mentioning that to increase the reliability of the results, three independent raters were asked to score the papers. To explore the students' perceptions on corpus- based teaching, the responses of the experimental group to the questionnaire was qualitatively examined and compared with the background questionnaire. To find out the retention difference of both groups in delayed posttest a matched T- test was conducted.

The following table displays the results of some statistical procedures performed on the scores of the subjects.

The following table displays the results of some statistical procedures performed on the scores of the subjects.

\section{Table 4.1}

The statistical procedures on IELTS writing test for both groups (test of homogeneity)

\begin{tabular}{|l|l|l|l|l|l|l|l|l|}
\hline Group & S & $\begin{array}{l}\text { M } \\
\text { S }\end{array}$ & $\begin{array}{l}\text { M } \\
\text { od }\end{array}$ & $\begin{array}{l}\text { Me } \\
\text { dia }\end{array}$ & $\begin{array}{l}\text { Vari } \\
\text { ance }\end{array}$ & $\begin{array}{l}\text { S } \\
\text { D }\end{array}$ & $\begin{array}{l}\text { Mini } \\
\text { mum }\end{array}$ & $\begin{array}{c}\text { Maxi } \\
\text { mum }\end{array}$ \\
\hline Contro & 1 & 5.7 & 4 & 5.25 & 3.08 & 7 & 3.25 & 8.75 \\
1 & 5 & 1 & & & & 5 & & \\
\hline Experi & 1 & 6.4 & 6.2 & 6.25 & 1.80 & 3 & 4.50 & 8.75 \\
mental & 5 & 6 & 5 & & & 4 & & \\
\hline
\end{tabular}




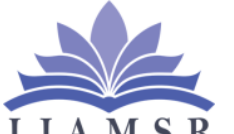

International Journal of Advanced Multidisciplinary Scientific Research (IJAMSR) ISSN:2581-4281

Based on the numerical information in Table 4.1, the homogeneity of the two groups was revealed statistically through performing $\mathrm{F}$ test formula at the 0.05 level of significance. Next, to answer the research questions and to know the effects of corpus-based conjunction units and retention, assessment was conducted at three points with three test sets. The pretest was conducted at the outset of the study to probe into learners' prior conjunction knowledge. After students completed the 2 units, the immediate posttest was used to evaluate their performances. The delayed posttest was then administered to investigate the students' retention of instructing conjunction about 2 weeks later.

The first research question asked whether or not the instruction of corpus-based conjunction materials in comparison with traditional instruction have any effect on Iranian EFL learners' writing.
Table 4.2:

The paired samples T-test for the comparison of pretest and posttest scores on Conjunction tests in each group

\begin{tabular}{|c|c|c|c|c|c|c|c|}
\hline Group & $\begin{array}{l}\text { Paire } \\
\text { d tests }\end{array}$ & $\mathbf{N}$ & $\begin{array}{c}\text { Mea } \\
\mathbf{n}\end{array}$ & SD & $\mathbf{t}$ & df & Sig. \\
\hline Control & $\begin{array}{c}\text { Pretest } \\
- \\
\text { posttes } \\
\text { t }\end{array}$ & $\begin{array}{l}1 \\
5\end{array}$ & -4.15 & $\begin{array}{c}3.7 \\
9\end{array}$ & $\begin{array}{c}4.2 \\
3\end{array}$ & $\begin{array}{l}1 \\
4\end{array}$ & $\begin{array}{c}0.00 \\
0\end{array}$ \\
\hline $\begin{array}{c}\text { Experiment } \\
\text { al }\end{array}$ & $\begin{array}{c}\text { Pretest } \\
- \\
\text { posttes } \\
\text { t }\end{array}$ & 5 & -5.61 & $\begin{array}{c}3.1 \\
2\end{array}$ & $\begin{array}{c}6.6 \\
6\end{array}$ & $\begin{array}{l}1 \\
4\end{array}$ & $\begin{array}{c}0.00 \\
1\end{array}$ \\
\hline
\end{tabular}

As the table shows, a significant difference between students' pretest and posttest scores in both groups was revealed. It indicated that both types of instruction (corpus-based and traditional) had positive effects. However, to reject the first null hypothesis, the total scores of both groups' posttsest were compared to see if there is a significant difference between their conjunction learning, using Independent Sample T-test. 
https://doi.org/10.31426/ijamsr.2018.1.9.915

\section{International Journal of Advanced Multidisciplinary Scientific Research (IJAMSR) ISSN:2581-4281}

Table 4.3:

The independent samples T-test for the comparison of the results of both groups in posttest on conjunction tests.

\begin{tabular}{|c|c|c|c|c|c|c|c|}
\hline Group & Test & N & Mea & SD & T & df & Sig. \\
\hline Control & posttes & 1 & 15.7 & 2.5 & & & \\
Experiment & $\mathrm{t}$ & 5 & 8 & 8 & 3.3 & 2 & 0.00 \\
al & posttes & 1 & 18.6 & 2.0 & 2 & 8 & 2 \\
& $\mathrm{t}$ & 5 & 1 & 4 & & & \\
\hline
\end{tabular}

As Table 4.3 shows, a significant difference between the scores of posttest of both groups was revealed. Therefore, it was concluded that the corpus-based instruction had more positive effects on the participants' writing ability to the extent that their differences are statistically significant $(\mathrm{p}=0.002<0.05)$.

The second research question asked whether or not the Iranian EFL learners' conjunction errors are reduced in essay writing after using the corpus-based materials in comparison with traditional teaching. To answer this question, the participants of both groups took part in IELTS essay writing tests. Then, based on the IELTS writing rubrics their papers were scored. Three independent raters participated in scoring the papers to increase the reliability. The statistical analyzes were then done based on the mean scores gained from the three independent raters' given scores for each participant. Again, the matched T-test was run to see if there were any statistically significant differences between the total scores of the participants' pretest and posttest in both groups. Table 4.4 reveals that there is a significant difference between the scores of the experimental group's members between pretest and posttest. However, this difference in the control group is not significant.

\section{Table 4.4:}

The paired samples T-test for comparison of both groups' Essay writing scores in pretest and posttest

\begin{tabular}{|c|c|c|c|c|c|c|c|}
\hline Group & $\begin{array}{l}\text { Paire } \\
\qquad \text { d } \\
\text { tests }\end{array}$ & $\mathbf{N}$ & $\begin{array}{l}\text { Me } \\
\text { an }\end{array}$ & SD & $t$ & $\begin{array}{l}\text { d } \\
\text { f }\end{array}$ & $\begin{array}{c}\text { Sig } \\
\text {. }\end{array}$ \\
\hline Control & $\begin{array}{c}\text { Prete } \\
\text { st- } \\
\text { postt } \\
\text { est }\end{array}$ & 5 & $\begin{array}{c}- \\
0.37\end{array}$ & $\begin{array}{c}0.9 \\
1\end{array}$ & $\begin{array}{c}- \\
1.7 \\
5\end{array}$ & 4 & $\begin{array}{l}0.1 \\
38\end{array}$ \\
\hline $\begin{array}{c}\text { Experime } \\
\text { ntal }\end{array}$ & $\begin{array}{l}\text { Prete } \\
\text { st- } \\
\text { postt } \\
\text { est }\end{array}$ & 5 & $\begin{array}{c}- \\
2.17\end{array}$ & $\begin{array}{c}1.4 \\
4\end{array}$ & $\begin{array}{c}- \\
5.8 \\
4\end{array}$ & 4 & $\begin{array}{l}0.0 \\
00\end{array}$ \\
\hline
\end{tabular}

Consequently, this finding suggests that the corpusbased instruction had a better effect and improved the writing ability of the members of the experimental group significantly. 


\section{International Journal of Advanced Multidisciplinary Scientific Research (IJAMSR) ISSN:2581-4281}

The third research question asked whether or not the use of corpus-based materials by Iranian EFL learners in comparison with traditional materials have any effect on the retention of what they have learned after a period of 2 weeks.

Table 4.5:

The paired samples T-test for the comparison of posttest and delayed posttest scores of conjunction tests for each group

\begin{tabular}{|c|c|c|c|c|c|c|c|}
\hline Group & $\begin{array}{c}\text { Paired } \\
\text { tests }\end{array}$ & $\mathbf{N}$ & $\begin{array}{c}\text { Mea } \\
\text { n }\end{array}$ & SD & $\mathbf{t}$ & df & Sig. \\
\hline Control & $\begin{array}{c}\text { Posttes } \\
\mathrm{t}- \\
\text { Delaye } \\
\mathrm{d} \\
\text { posttest }\end{array}$ & 5 & 1.13 & $\begin{array}{c}0.7 \\
3\end{array}$ & $\begin{array}{c}6.0 \\
0\end{array}$ & 4 & $\begin{array}{c}0.00 \\
0\end{array}$ \\
\hline $\begin{array}{c}\text { Experiment } \\
\text { al }\end{array}$ & $\begin{array}{c}\text { Posttes } \\
\mathrm{t}- \\
\text { Delaye } \\
\mathrm{d} \\
\text { posttest }\end{array}$ & 5 & 0.18 & $\begin{array}{c}0.3 \\
4\end{array}$ & $\begin{array}{c}2.0 \\
4\end{array}$ & 4 & 0.06 \\
\hline
\end{tabular}

As it is observed in Table 4.5, there is no significant difference between posttest and delayed posttest scores of members of the experimental groups. This finding indicates that corpus-based instruction had a positive effect on the students' retention after a period of two weeks and they could remember what they had learned. It is worth to mention that during these two weeks there was no instruction for any group.

And finally the fourth supplementary research question asked about the participants' attitudes about using corpus-based instruction. To answer this question, a background questionnaire consisting of 15 items was given to both groups. The purpose of this questionnaire was to inform the students of the objective of the study; second, to use the results for further comparison. The questionnaire included students' $(\mathrm{N}=30)$ attitudes about their English writing ability (items1, 2,3) and their writing problems (items4, 5,6,7). It also inquired about those who agree (technology proponents) with using technology in teaching English (items 9,10,11,12,13,15) and those who do not (technology opponents) (items $8,14)$. The results show that $63 \%$ of the participants had problems in writing English texts; $46 \%$ had problems with connecting the sentences together and creating coherence, using the correct form of vocabularies and structure; $57 \%$ were in favor of using technology in teaching English, and 17\% disagreed. Then, in the posttest phase, another 17-item questionnaire was given to the members of the experimental group to check their perceptions about corpus-based instruction. The questionnaire included questions about the participants' attitudes about corpus (items 1,3,4,5,6,17); the problems they faced in this method (items 7,8,9,10,11); the practice phase of the study (items2,12); and if they would like to use corpus in future learning practices, (items 13,14,15,16).

The results show that $73.33 \%$ of the participants were in favor of using corpus in teaching conjunction and writing in general; $60 \%$ did not face any special problem 


\section{International Journal of Advanced Multidisciplinary Scientific Research (IJAMSR) ISSN:2581-4281}

using the corpus; $73 \%$ believed that the practice sessions were helpful enough for learning the method; and $80 \%$ indicated that they will refer to corpus in future for learning conjunctions and writing in general.

\section{Discussion and Conclusion}

The findings of this study suggest that using corpusbased conjunction materials have a great impact on the participants' learning of conjunction and their writing ability in general. Conjunctions as discourse markers are cohesive devices which bring coherence to the meaning of a discourse. Consequently, if we find ways through which we can teach conjunctions more effectively, students' overall writing ability will improve. Fortunately, the present study revealed that corpus-based materials have a positive effect in comparison with the traditional methods and the authentic examples of corpus-based concordancing can help university EFL students write more accurate and appropriate essays. It also showed that naturally-occurring, context-based or discourse-based language learning had a better effect in comparison with detached and artificial language practices. Also, learners can take more control of their learning and work at their own pace with corpus-based materials and consequently it makes the learners' selfdependent.

It was also found out that the corpus-based practices had a great impact on the retention of knowledge of the students. It may be concluded that more senses are involved in these types of practices which should be, however, examined in further researches.

The participants' positive feedbacks also indicated that corpus-based materials as a complementary method can bring variety to the learning environment and it has a positive effect on their learning in comparison with the monotonous "book and board" atmosphere of the class. The participants of this study really welcomed this method.

The rapid growth of knowledge rate necessitates anytime, anywhere teaching methods which provide the learners with the suitable situation for learning at any moment. Fortunately, the development of technology has established the basis for such teaching methods. Therefore, each nation, to keep pace with this rapid development, should find the ways of how to include the technology in schools which are the building blocks of each society. As a necessary step, students should be taught how to use the technology. Using the computers as a source of information about the foreign language in the classroom requires more than simply giving students direct access to data.

Corpora seem to significantly enrich the learning environment, by providing opportunities for using English and observing regularities in this use. At the same time they can reduce the learner's dependency on the teacher, and the teacher's dependency on the textbook, allowing teachers to concentrate on their roles as facilitators of learning rather than language experts. It also gives learners this chance to familiarize with different language contexts, genres, and frequency of occurrences of different elements of the language.

Regarding the topic under investigation the present research revealed that much attention must be paid in conjunction as discourse markers. In addition, students should become conscious about conjunction use in learning English and should pay more attention to them as necessary devices to create a coherent text. 


\section{International Journal of Advanced Multidisciplinary Scientific Research (IJAMSR) ISSN:2581-4281}

There are some limitations which should be improved, including the small size of the sample and the time allocated to the study. Students' motivation to use online materials needs to be boosted to increase their attention to the conjunction units and to answer the questions more accurately and attentively. Corpus-based homework is also helpful. Other studies also suggest: 1) to investigate the effects of corpus-based materials with the performance of students on listening, speaking and reading and on other parts of grammatical structures, vocabularies, etc. and 2) to discover whether there are differential effects on learners at different proficiency levels of EFL.

\section{References}

1) Carter, R. \& D. Nunan (2001). The Cambridge Guide to Teaching English to speakers of Other Languages. Cambridge: Cambridge University Press.

2) Crewe, W. J. (1990). The Illogic of Logical Connectives. In Tseng, Y. \& H. Liou (2005). "The Effects of Online Conjunction Materials on College EFL students' Writing" System, 34. 270-283.

3) Dodd, B. (2000). The Relevance of Corpora to German Studies. A paper presented on line. Birmingham.

4) Egbert, J. L. (2005). Conducting Research on CALL. Mahwah, NJ: Lawrence Erlbaum.

5) Faghih, E. (2000). Disjunctive and Coordinate Conjunctions as Markers of Competency in EFL. Journal of Humanities, 10(36), 7-20.

6) Field, Y.\& L.M.O. Yip (1992). A comparison of internal conjunctive cohesion in the English essay writing of Cantonese speakers and native speakers. RELC Journal, 23(1), 15-28.

7) Granger, S. \& S. Tyson (1996). Connector Usage in the English Essay Writing of Native and Non-native EFL Speakers of English. . In Tseng, Y. \& H. Liou
(2005). "The Effects of Online Conjunction Materials on College EFL students' Writing” System, 34. 270-283.

8) Halliday, M. A. K. \& R. Hasan (1976). Cohesion in English. London: Longman.

9) Hanson-Smith, E. (2000). Technology-Enhanced Learning Environment. Alexanderia, VA: TESOL.

10) Krashen, S. D. (1985). The Input Hypothesis. London: Longman.

11) Levy, M. (1997). Computer-assisted Language Learning: Context and Conceptualization. Oxford, England: Clarendon Press.

12) Renkema, J. (1993). Discourse Studies, An Introductory Textbook. Amesterdam: Tilburg University.

13) Rutherford, W. \& M. Sharwood-Smith (1985). Consciousness-raising and Universal Grammar. Applied Linguistics 6: 274-282.

14) Schiffrin, D. (1986). Discourse Markers, Studies in Interactional Sociolinguistics5. Cambridge: Cambridge University Press.

15) Sinclair, J. (1991). Corpus, Concordance, Collocation. Oxford: Oxford University Press.

16) Tseng, Y. \& H. Liou (2005). "The Effects of Online Conjunction Materials on College EFL students' Writing” System, 34: 270-283.

17) Warschauer, M. (1996). Comparing Face-to-Face and Electronic Communication in the Second Language Classrom. CALICO Journal, 13(2): 7-26.

18) Zamel, V. (1983). Teaching those Missing Links in Writing. . In Tseng, Y. \& H. Liou (2005). “The Effects of Online Conjunction Materials on College EFL students' Writing” System, 34: 270-283. 